\title{
Ultrasound-assisted emulsification microextraction and preconcentration of trace amounts of silver ions as a cyclam complex
}

\author{
Gholamreza Khayatian ${ }^{*}$ and Bahareh Pourbahram
}

\begin{abstract}
Background: Silver has been recognized as a toxic element for biological systems. A low level of exposure to silver compounds is widespread owing to the use of soluble silver compounds to disinfect water for drinking and reaction purposes. The present paper describes an ultrasound-assisted emulsification microextraction method for the preconcentration and determination of silver ions in drinking water.

Methods: Determination was carried out using 1,4,8,11-tetraazacyclotetradecane as a complexing reagent and chloroform as extracting solvent, followed by flame atomic absorption determination of silver ions.

Results: The main factors affecting microextraction efficiency, such as extraction solvent type and volume, concentration of chelating reagent, concentration of picrate ions, and $\mathrm{pH}$, were optimized. Under optimal conditions, a limit of detection and enrichment factor of $6.79 \mathrm{ng} \mathrm{mL}^{-1}$ and 9.8 were obtained for silver ions, respectively. The analytical curve was linear in the range of $0.055-1.5 \mathrm{\mu g} \mathrm{mL}^{-1}$, with a correlation coefficient $\left(R^{2}\right)$ of 0.997 .

Conclusions: The use of ultrasound as a powerful energy for the microextraction and determination of silver was proposed. The main advantages of the method are as follows: minimum use of toxic organic solvent and wide linear dynamic range.
\end{abstract}

Keywords: Ultrasound-assisted emulsification microextraction, Silver extraction, 1,4,8,11-tetraazacyclotetradecane

\section{Background}

The increasing use of silver compounds and silvercontaining preparations in the industry such as disinfectants and photographic films has resulted in an increased silver content of environmental samples (Kolthoff and Elving 1966; Meian 1991). Thus, accurate determination of trace quantities of silver ions by simple methods is important in chemical and environmental analysis. Direct determination of silver ions of trace level is usually very limited due to the complexity of the sample matrix and the low concentrations of silver ions; therefore, there is a crucial need for the extraction and preconcentration of this element from the sample matrix before its analysis using atomic absorption spectrometry

* Correspondence: gkhayatian@yahoo.com

Chemistry Department, University of Kurdistan, Sanandaj, Iran
(Xie et al. 2005). The most widely used techniques for separation and preconcentration of trace amounts of silver ions are coprecipitation (Mao et al. 1998), solidphase extraction (SPE) (Rofouei et al. 2009; Shamsipur et al. 2002; Safavi et al. 2004; Khayatian and Hassanpoor 2012a), liquid-liquid extraction (LLE) (Koh and Sugimoto 1996), and cloud point extraction (CPE) (Manzoori et al. 2007 and Dalali et al. 2008). However, most of these methods are laborious, time-consuming, and require large volumes of toxic organic solvents.

It is well known that ultrasound is a powerful energy for the acceleration of various steps in analytical procedures, such as homogenizing and emulsion forming (Aydin et al. 2006). This type of energy greatly helps in the processes of extraction and preconcentration because it facilitates the acceleration of the mass-transfer 
process between two immiscible phases (Ozcan et al. 2009). This leads to an increase in the extraction efficiency of the method within a minimum span of time (Luque de Castro and Priego-Capote 2006 and Khayatian and Hassanpoor 2013). As a result, the application of ultrasound radiation to an extraction method such as liquid-liquid extraction provides the advantages of both methods. This new technique is called ultrasound-assisted emulsification microextraction (USAEME). This extraction method offers advantages such as simplicity, rapidity, a high enrichment factor, and safety and low cost due to consumption of very small amounts of toxic organic solvents. In USAEME, an extraction solvent is rapidly injected into an aqueous sample with a syringe. After sonication, a cloudy solution is formed, and the analyte is extracted into the fine droplets of the extraction solvent. After extraction, the phase separation is performed by centrifugation, and the analyte is determined in the sedimented phase by instrumental methods.

In recent years, the USAEME method has been used for the separation and preconcentration of cadmium ( $\mathrm{Li}$ et al. 2009 and Ma et al. 2009; Khan et al. 2014), palladium (Mohamadi and Mostafavi 2010), gold (De La Calle et al. 2011), silver (Wen et al. 2012), Te(IV) (Fathirada et al. 2012), mercury (Stanisz et al. 2013), and from environmental matrices. However, among many types of ligands used in microextraction of metal ions, less attention has been directed toward using macrocyclic crown ethers as an extracting agent. Therefore, we decided to study application of crown ethers as a new extracting agent for developing a sensitive microextraction method for the determination of silver ions.

In the present work, we report a simple USAEME method for the preconcentration and flame atomic absorption spectrometry (FAAS) determination of silver ions using 1,4,8,11-tetraazacyclotetradecane (cyclam) as a complexing agent and $\mathrm{CHCl}_{3}$ as an extraction solvent.

\section{Methods}

\section{Chemicals and reagents}

Extra pure methanol $\geq 95.5 \%$, acetonitrile (AN) $\geq 99 \%$, nitric acid $65 \%$, and hydrochloric acid $32 \%$ were used as received. Stock standard solution $\left(1.000 \mathrm{~g} \mathrm{~L}^{-1}\right)$ of $\mathrm{Ag}^{+}$was prepared by dissolving corresponding $\mathrm{AgNO}_{3}$ (Merck) $(99.8-100.5 \%)$ in distilled water. The ligand that was used for the extraction procedure was 1,4,8,11-tetraazacyclotetradecane (cyclam, Merck) $\geq 92.0 \%$ and used without any further purification, except for vacuum drying over $\mathrm{P}_{2} \mathrm{O}_{5}$.

Determination of silver and other cations was performed on a Shimadzu AA-670 atomic absorption spectrometer (Kyoto, Japan) under the recommended conditions (wavelength of $328.1 \mathrm{~nm}$ and bandwidth $0.6 \mathrm{~nm})$. All pH measurements were made using a Metrohm E-691 digital pH meter with a combined glass electrode. A model Labofuge 400 (Germany) centrifuge was used to accelerate phase separation. A model Parsonic $7500 \mathrm{~S}, 28-\mathrm{kHz}, 100-\mathrm{W}$ (220 VAC max) ultrasonic bath with temperature control was used to assist the emulsification process of the microextraction technique.

\section{General procedure}

A $5.0-\mathrm{mL}$ sample containing $2.5 \mu \mathrm{g} \mathrm{\textrm {L } ^ { - 1 }}$ of silver ion standard solution or real sample adjusted at $\mathrm{pH}=2$ was placed in a $15-\mathrm{mL}$ conical-bottom glass centrifuge tube and then $200 \mu \mathrm{L}$ of cyclam in chloroform $\left(9.27 \times 10^{-4}\right.$ M) was added. After sonication for about $14 \mathrm{~min}$ at $35^{\circ}$ $\mathrm{C}$, a stable cloudy solution was obtained and $\mathrm{Ag}^{+}$-cyclam 1:1 complex was extracted into the fine droplets of the $\mathrm{CHCl}_{3}$. The mixture was then centrifuged for $5 \mathrm{~min}$ at $2500 \mathrm{rpm}$. Consequently, the fine droplets of the $\mathrm{CHCl}_{3}$ settled at the bottom of the centrifuge tube. After removing the whole sedimented phase with a microsyringe, the sedimented phase was evaporated to dryness (Scheme 1). After evaporation of the organic phase, $0.5 \mathrm{~mL}$ of $\mathrm{Na}_{2} \mathrm{~S}_{2} \mathrm{O}_{3} \quad 1.0 \mathrm{M}$ was added and $\mathrm{Ag}^{+}$in this

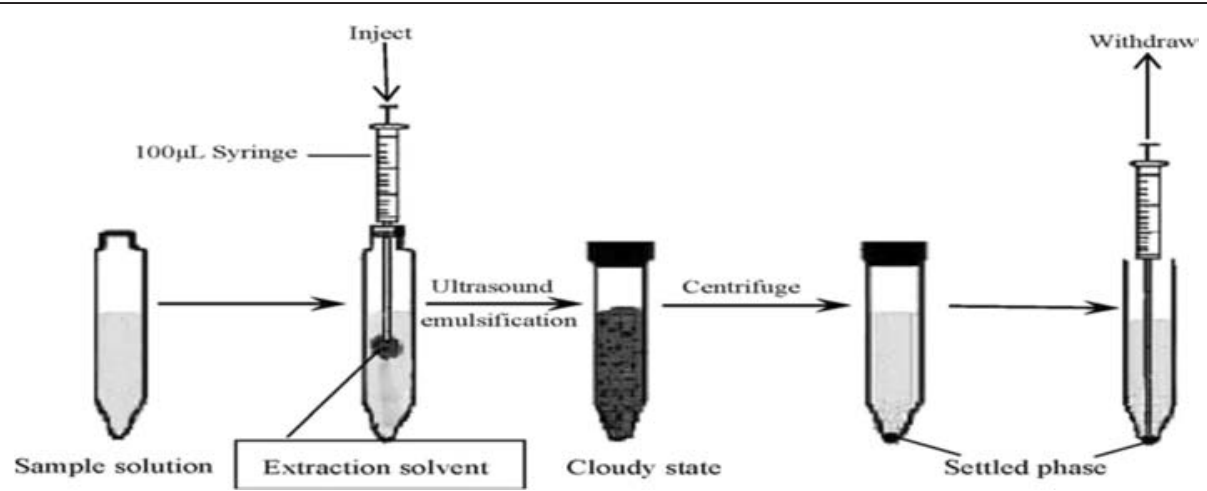

Scheme 1 Schematic representation of USAEME enrichment method 
solution was determined by FAAS (Khayatian and Hassanpoor 2012b and Khayatian and Hassanpoor 2013).

\section{Preparation of radiological film}

A $2-\mathrm{cm}^{2}$ sheet of a developed film $(0.0504 \mathrm{~g})$ was cut into several strips and put into a $100-\mathrm{mL}$ beaker. Then, $0.5 \mathrm{~mL}$ of concentrated sulfuric acid was added, followed by six to eight drops of concentrated nitric acid. The beaker was placed on the hot plate and heated until evolution of brown fumes was no longer observed. This procedure was repeated until the radiological film was digested. After complete decomposition, the contents of the beaker should consist of a white to very light tan precipitate and a clear yellowish liquid. The hot plate was set on high heat, and the contents of the beaker were boiled until white fumes appeared (Gansel 1959; Sarafraz-Yazdi and Amiri 2010). Then, the analysis was performed as mentioned previously after diluting the solution 50 times and adjusting the $\mathrm{pH}$ with sodium hydroxide to $\mathrm{pH} 2$.

\section{Results and discussion}

\section{Optimization of parameters}

To obtain high extraction efficiency, the effects of different parameters such as type and volume of the extracting solvent, $\mathrm{pH}$, amount of cyclam, amount of counter ion, extraction time, salt addition, and centrifuging time were optimized. Then, the effect of interfering ions was investigated, and different natural water samples and a radiological film sample were subjected to analysis via the recommended method to evaluate the concentration of silver ions.

\section{The effect of type and volume of the extraction solvent} The extracting solvent in USAEME should be able to form a cloudy solution in the aqueous phase; in addition, it must have high extraction efficiency and low water solubility (Manzoori et al. 2007; Safavi et al. 2004). Thus, to study the type of extraction solvent, different solvents such as chloroform, dichloromethane, carbon tetrachloride, chlorobenzene, and tetrachloroethylene were examined. For this purpose, $200 \mu \mathrm{L}$ of each solvent was added to $5.0 \mathrm{~mL}$ of deionzed water containing $0.5 \mu \mathrm{g} \mathrm{mL}^{-1}$ of silver ions, and the extraction efficiency of silver ions was measured by the increase in absorbance in the extracted solvent. The obtained results showed that chloroform has the highest extraction efficiency for the silver ions; thus, chloroform was selected as the extraction solvent for further experiments, Table S1 (in Additional file 1).

The influence of the amount of chloroform used in USAEME of silver ions was also investigated. Experiments were performed using volumes of chloroform ranging from 30 to $400 \mu \mathrm{L}$. The results are shown in Fig. 1 . As can be seen, the absorbance of silver ions increased along with the increase of volume of chloroform from 30 to $100 \mu \mathrm{L}$ and then remained constant when the volume was continuously increased. The increase in the absorbance is due to the increase in the volume of chloroform. This can increase the amount of extracted silver-cyclam ion complex. Thus, in the further studies, $200 \mu \mathrm{L}$ of chloroform was selected as the optimum volume of the extraction solvent.

\section{Effect of $\mathrm{pH}$ on the extraction of silver ions}

The effect of the $\mathrm{pH}$ of the sample solution on the recovery of $0.5 \mu \mathrm{g} \mathrm{mL}{ }^{-1}$ of silver ions from the $5.0-\mathrm{mL}$ solution was investigated in the $\mathrm{pH}$ range of 2.0-7.0. The $\mathrm{pH}$ was adjusted by using $0.1 \mathrm{M}$ of either nitric acid or sodium hydroxide solutions. The results of percent of extraction versus $\mathrm{pH}$ value are shown in Figure S1 (Additional file 1). As can be seen, the results indicated that the silver ions can be quantitatively extracted at $\mathrm{pH}$ $2.0(\geq 95 \%)$, and then, at higher $\mathrm{pH}$ values, percent extraction slowly decreased. Low extractions that occur at lower $\mathrm{pH}$ values ( $\mathrm{pH}$ 1.0) are probably due to protonation of the ligand. At higher $\mathrm{pH}$ values $(\mathrm{pH}>3.0)$, the extraction efficiency gradually decreases, which may be

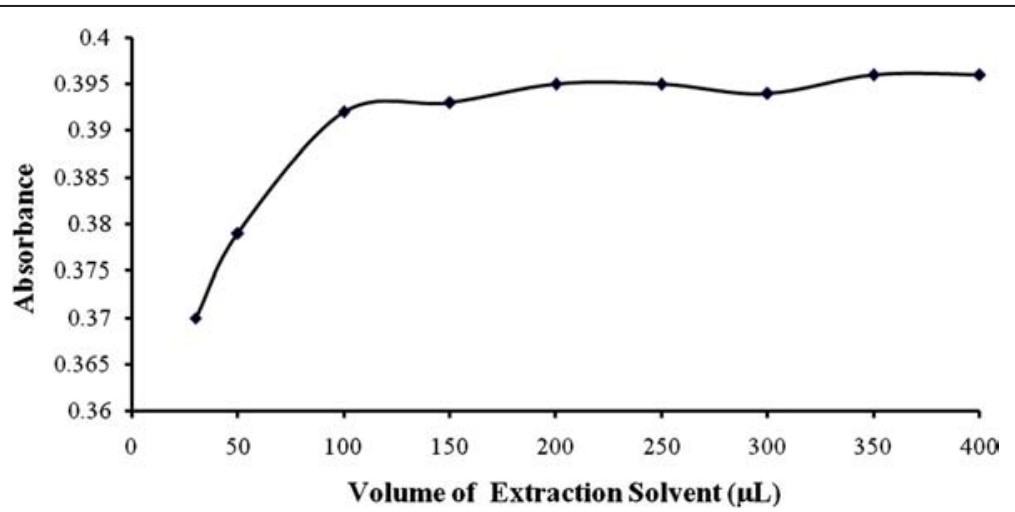

Fig. 1 Effect of volume of extraction solvent. Conditions: sample volume $5.0 \mathrm{~mL}$; sample concentration $0.5 \mu \mathrm{g} \mathrm{mL}{ }^{-1}$; picric acid concentration $1 \times 10^{-3} \mathrm{M}$ 
due to the addition of sodium hydroxide for the adjustment of higher $\mathrm{pH}$ values and the competition of this ion with silver ion for complex formation with cyclam. Thus, $\mathrm{pH} 2.0$ was chosen as the optimum $\mathrm{pH}$ for further studies.

\section{Effect of cyclam concentration on the extraction of silver ions}

The effect of cyclam concentration on the absorbance of silver ions has been studied in the concentration range of $9.27 \times 10^{-3}$ to $9.27 \times 10^{-5} \mathrm{M}$, and the results are shown in Fig. 2. As can be seen, the absorbance signal increases with the increase of the ligand concentration, and then, a maximum is obtained after the ligand concentration approaches to $9.27 \times 10^{-4} \mathrm{M}$. However, the signal was not altered by the addition of ligand up to $9.27 \times 10^{-5} \mathrm{M}$. This observation may be due to the quantitative extraction of silver ions in such a condition (Khayatian and Hassanpoor 2012a and Shamsipur et al. 2002). Thus, a concentration of $9.27 \times 10^{-4} \mathrm{M}$ was selected as a suitable amount of the cyclam for further studies.

\section{Effect of counter ions on silver ions absorbance}

The silver ion extraction depends not only on the various kinds of counter anions used but also on the concentration of these ions; therefore, different types of counter ions, such as $\mathrm{NO}_{3}^{-}, \mathrm{ClO}_{4}^{-}$, and picrate ion (from picric acid), were chosen for the extraction of silver ions. Among the different counter ions studied, the picrate ion was the best for the extraction of silver ions from the sample solution. This observation is due to a more lipophilic character of picrate ions that not only neutralize the charged $\left(\mathrm{Ag}^{+}\right.$-cyclam) complexes but also increase a more lipophilic character to the silver-cyclam complex. These effects cause greater extraction of silver ions than the inorganic anions such as $\mathrm{NO}_{3}^{-}$and $\mathrm{ClO}_{4}^{-}$can provide (Shamsipur and Khayatian 2001 and Shamsipur et al. 2003; Rounaghi et al. 2008).

The effect of concentration of picric acid in the silver ion extraction was investigated in the concentration range of $0.001-0.025 \mathrm{~mol} \mathrm{~L}^{-1}$, and the results are shown in Fig. 3. As seen, the absorbance signal increases with increasing picric acid concentration in the sample solution. The maximum absorbance occurs when the concentration of picric acid is about $0.006 \mathrm{~mol} \mathrm{~L}^{-1}$ and then it decreases gradually with increasing picric acid concentration. The decrease in the extraction of silver ions at a higher concentration of picric acid may be due to a competitive effect between hydronium ions (from picric acid) with silver ions, which causes a decrease in extraction efficiency of silver ions from aqueous phase to organic phase.

\section{Effect of extraction time}

In USAEME, extraction time is defined as the time between the addition of extraction solvent and the end of the sonication stage (Zhang et al. 2011). Enough sonication time will make the extraction solvent disperse more finely into the aqueous solution and results in an excellent cloudy solution and better extraction efficiency. So, the effect of extraction time on the extraction of silver ions was evaluated in the range of 4-20 min. The results are shown in Fig. 4. It was observed that the highest absorbance signal was obtained at $14 \mathrm{~min}$ (under constant ultrasonic power) and then it decreased with the increase in sonication time. The decrease in the absorbance signals at a time greater than 14 min may be due to an increase in the solubility of the ligand in the aqueous

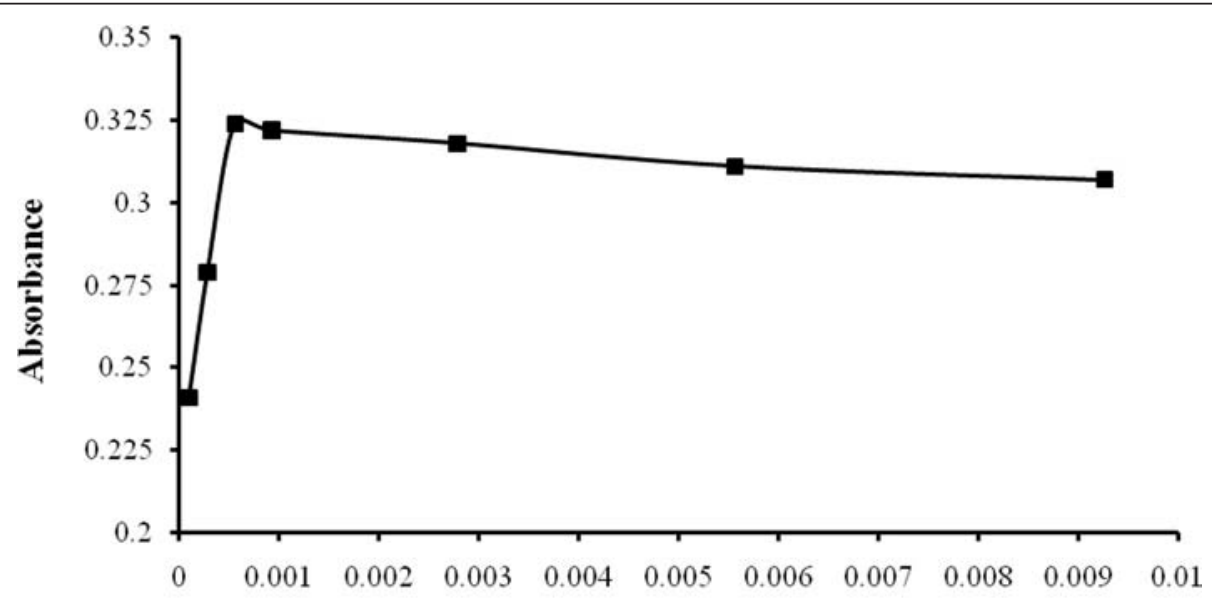

Concentration of Cyclam (M)

Fig. 2 Effect of cyclam concentration on USAEME of silver ions. Conditions: sample volume $5.0 \mathrm{~mL}$; sample concentration $0.5 \mu \mathrm{g} \mathrm{LL}^{-1}$; picric acid concentration $1 \times 10^{-3} \mathrm{M}$ 


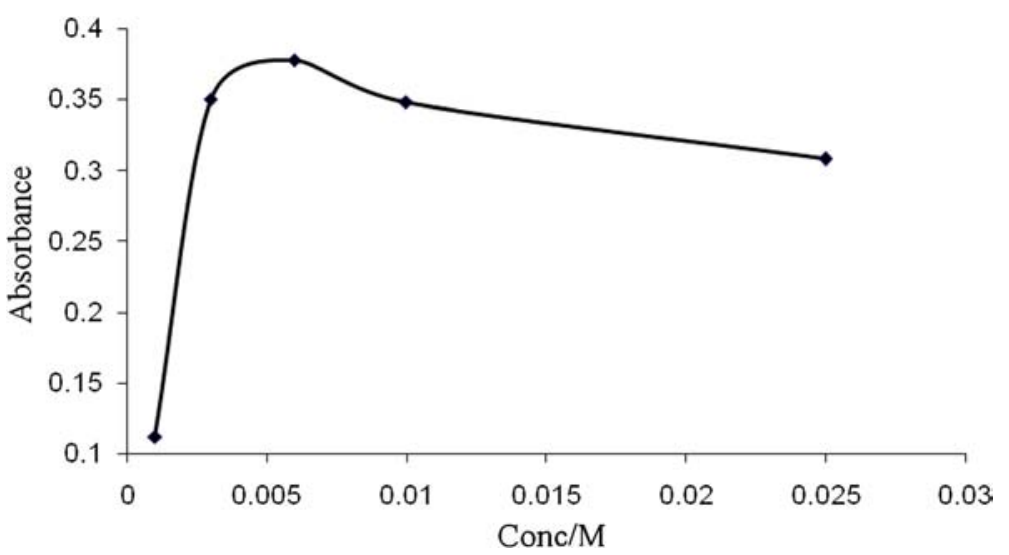

Fig. 3 Effect of picric acid concentration on the USAEME of silver ions. Conditions: sample volume $5.0 \mathrm{~mL}$; sample concentration $0.5 \mu \mathrm{m} \mathrm{L}^{-1}$; extraction solvent volume $\left(\mathrm{CHCl}_{3}\right) 200 \mu \mathrm{L}$; different concentrations of picric acid

phase (Hashemi et al. 2013). Based on these observations, an extraction time of $14 \mathrm{~min}$ was chosen for further experiments.

\section{Effect of ionic strength}

In the extraction methods, due to salting-out effect, the solubility of metal chelates in aqueous solutions decreases with increasing ionic strength. Thus, for this purpose, extraction efficiency was investigated by the addition of varying concentrations of $\mathrm{NaNO}_{3}$ and $\mathrm{NaClO}_{4}$ salts from 0 to $10 \%$. Increasing the salt concentration had no significant effect on extraction efficiency, perhaps because of the dual effects of salt addition in USAEME: one involves increasing the volume of the extracted phase, which decreases the enrichment factor, and the other is the salting-out effect that increases the enrichment factor (Zeini Jahromi et al. 2007 and Bidari et al. 2007). These two effects cancel each other out; therefore, the enrichment factor is nearly constant by increasing the amount of the salts, and the extraction experiments were carried out without additional salt.

\section{Effect of time and rotational speed of the centrifugation step on extraction}

The effect of centrifugation time on extraction of silver ions was evaluated in the range of 3-9 $\mathrm{min}$, while all of the experimental parameters were kept constant. The obtained results showed that absorbance signals increase slowly by increasing the centrifugation time until $5 \mathrm{~min}$ and then it remains constant with further increase in centrifugation time (Additional file 1: Figure S2). The effect of centrifugation speed was also investigated in a rotational speed of 1000-3500 rpm (Additional file 1: Figure S3). The results showed that the best rotational speed for extraction is $2500 \mathrm{rpm}$. Therefore, a centrifugation time of $5 \mathrm{~min}$ at a rotational speed of $2500 \mathrm{rpm}$ was chosen for further experiments.

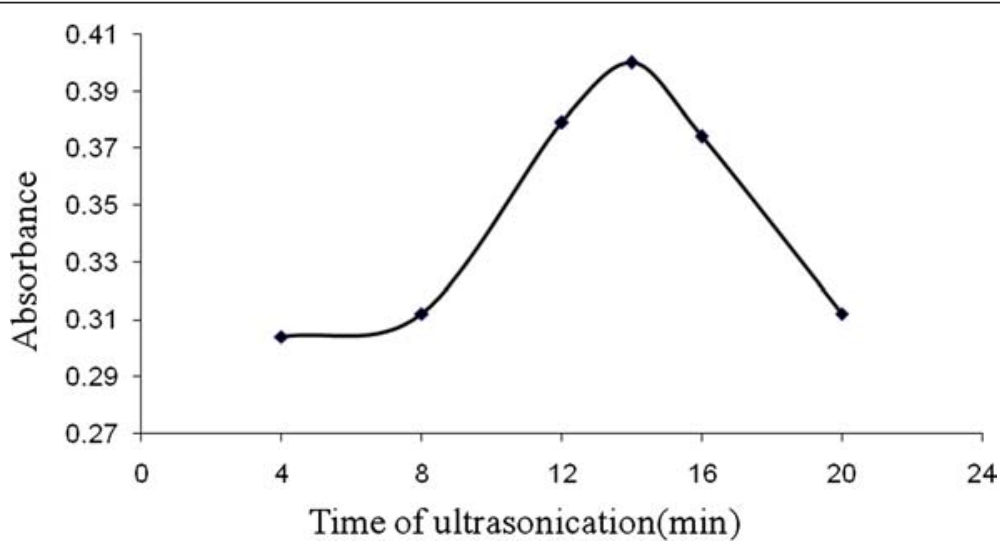

Fig. 4 Effect of time of extraction on USAEME of silver ions. Conditions: sample volume $5.0 \mathrm{~mL}$; sample concentration $0.5 \mu \mathrm{g} \mathrm{mL} \mathrm{m}^{-1}$; extraction solvent volume $\left(\mathrm{CHCl}_{3}\right) 200 \mu \mathrm{L}$; picric acid concentration $6 \times 10^{-3} \mathrm{M}$ 
Table 1 Tolerant limits of coexisting ions for the extraction of $0.5 \mu \mathrm{g} \mathrm{mL}^{-1}$ silver ions

\begin{tabular}{|c|c|c|c|}
\hline Interference ion & Added as & Tolerance limit ion ratio(Cion/CAg) & $\%$ Recovery \\
\hline $\mathrm{Mg}^{2+}$ & $\mathrm{Mg}\left(\mathrm{NO}_{3}\right)_{2}$ & 1000 & $96 \pm 3$ \\
\hline $\mathrm{K}^{+}$ & $\mathrm{KNO}_{3}$ & 100 & $95.1 \pm 2.2$ \\
\hline $\mathrm{Ca}^{2+}$ & $\mathrm{Ca}\left(\mathrm{NO}_{3}\right)_{2} \cdot 4 \mathrm{H}_{2} \mathrm{O}$ & 10 & $95.4 \pm 2.5$ \\
\hline $\mathrm{Co}^{2+}$ & $\mathrm{Co}\left(\mathrm{NO}_{3}\right)_{2} \cdot 6 \mathrm{H}_{2} \mathrm{O}$ & 10 & $97.1 \pm 3.4$ \\
\hline $\mathrm{Cd}^{2+}$ & $\mathrm{Cd}\left(\mathrm{NO}_{3}\right)_{2} \cdot 6 \mathrm{H}_{2} \mathrm{O}$ & 10 & $96.0 \pm 1.5$ \\
\hline $\mathrm{Hg}^{+}$ & $\mathrm{Hg}_{2}\left(\mathrm{NO}_{3}\right)_{2}$ & 5 & $95.4 \pm 2.3$ \\
\hline $\mathrm{Al}^{3+}$ & $\mathrm{Al}\left(\mathrm{NO}_{3}\right)_{3}$ & 5 & $97.32 \pm 2.4$ \\
\hline $\mathrm{Na}^{+}$ & $\mathrm{NaNO}_{3}$ & 5 & $96.3 \pm 3.3$ \\
\hline $\mathrm{Mn}^{2+}$ & $\mathrm{Mn}\left(\mathrm{NO}_{3}\right)_{2} \cdot 4 \mathrm{H}_{2} \mathrm{O}$ & $5^{a}$ & $95.0 \pm 2.3$ \\
\hline $\mathrm{Pb}^{2+}$ & $\mathrm{Pb}\left(\mathrm{NO}_{3}\right)_{2}$ & 1 & $94.0 \pm 3.5$ \\
\hline $\mathrm{Hg}^{2+}$ & $\mathrm{Hg}\left(\mathrm{NO}_{3}\right)_{2}$ & $1^{\mathrm{a}}$ & $98.8 \pm 1.4$ \\
\hline $\mathrm{Ni}^{2+}$ & $\mathrm{Ni}\left(\mathrm{NO}_{3}\right)_{2}$ & $5^{\mathrm{a}}$ & $95.35 \pm 2.5$ \\
\hline $\mathrm{Fe}^{3+}$ & $\mathrm{Fe}\left(\mathrm{NO}_{3}\right)_{3} \cdot 9 \mathrm{H}_{2} \mathrm{O}$ & $1^{\mathrm{b}}$ & $95.76 \pm 3.4$ \\
\hline $\mathrm{NO}_{3}^{-}$ & $\mathrm{KNO}_{3}$ & 100 & $95.2 \pm 3.5$ \\
\hline $\mathrm{CO}_{3}^{2-}$ & $\mathrm{K}_{2} \mathrm{CO}_{3}$ & 100 & $95.0 \pm 4.3$ \\
\hline $\mathrm{OAC}^{-}$ & $\mathrm{CH}_{3} \mathrm{COOK}$ & 25 & $100.4 \pm 1.3$ \\
\hline $\mathrm{Cl}^{-}$ & $\mathrm{KCl}$ & 10 & $95.06 \pm 3.2$ \\
\hline
\end{tabular}

${ }^{a}$ The interference effect in the presence of EDTA

${ }^{\mathrm{b}}$ The interference effect in the presence of $\mathrm{F}^{-}$

\section{Effect of interfering ions}

In order to investigate potential interferences on the recovery of silver ions, a $5.0-\mathrm{mL}$ aliquot solution containing $0.5 \mu \mathrm{g} \mathrm{L}^{-1}$ silver ions with various amounts of diverse ions was treated according to the recommended procedure. A given species was considered to interfere if it resulted in a $\pm 5 \%$ variation of the absorbance signal. The results are given in Table 1. As can be seen, some of the investigated ions have no significant influence on the extraction of silver ions under the selected conditions. Sil et al. (2001) showed that cyclam has a greater preference for silver ions over other cations. This behavior is due to substitution of $\mathrm{NH}$ groups in a macrocyclic ring that increases the stability of $\mathrm{Ag}^{+}$complexes significantly.

\section{Analytical performance and method validation}

The analytical characteristics of the recommended method, including linear range, limit of detection (LOD), limit of quantification (LOQ), relative standard deviation (RSD), correlation coefficient $\left(R^{2}\right)$, and enrichment factor, were obtained. Under the optimum experimental conditions, the analytical curve was achieved by analyzing $5.0 \mathrm{~mL}$ of silver ion standard solution containing a known amount of target ion in the range of $0.01-2.5 \mu \mathrm{g} \mathrm{mL} \mathrm{L}^{-1}$. The analytical curve was linear in the range of $0.055-1.5 \mu \mathrm{g} \mathrm{mL}^{-1}$ with a correlation coefficient $\left(R^{2}\right)$ of 0.997 . The regression equation was $A=0.853 C-0.019$, where $A$ is the absorbance and $C$ is the concentration of silver in micrograms per milliliter. The limit of detection $\left(n=10, \mathrm{LOD}=3 \sigma_{\mathrm{blank}} / m\right)$ and limit of quantification $\left(n=10, \mathrm{LOQ}=10 \sigma_{\text {blank }} / m\right)$, where $m$ is the slope of the analytical curve in accordance to IUPAC recommendation, were obtained 6.79 and $22.77 \mathrm{ng} \mathrm{mL}^{-1}$, respectively. The RSD for 15 replicate measurements of $0.5 \mathrm{mg} \mathrm{L}^{-1}$ of silver ions was 5.50 , and the recovery of extraction calculated according to $\left(C_{\text {org }} V_{\text {org }}\right) /\left(C_{\text {aq }} V_{\text {aq }}\right) \times 100$, where $C_{\mathrm{org}}$ and $C_{\mathrm{aq}}$ are the concentrations of silver in the organic phase and sample solution, respectively, and $V_{\text {org }}$ and $V_{\mathrm{aq}}$ are the volumes of the organic and the sample solutions, respectively, was about $98.5 \%$.

\section{Applications}

The developed method was applied for the extraction and determination of silver ions in well water and radiological film, and the results along with the recovery for the spiked

Table 2 The application of the USAEME method for determination silver ions in water and radiological film samples

\begin{tabular}{llll}
\hline Sample & Added $\left(\mu \mathrm{g} \mathrm{mL}^{-1}\right)$ & Found $\left(\mu \mathrm{g} \mathrm{mL}^{-1}\right)$ & Recovery $(\%)$ \\
\hline Well water & 0.00 .1 & $<\mathrm{LOD}^{\mathrm{a}} 0.0943 \pm 0.012^{\mathrm{b}}$ & 93 \\
Radiological film & 0.00 .5 & $0.575 \pm 0.0181 .103 \pm 0.016$ & -105 \\
\hline
\end{tabular}

Below limit of detection

${ }^{\mathrm{b}}$ Mean \pm standard deviation (SD) for $(N=3)$ 
Table 3 Comparison of the published preconcentration methods for silver ion with the recommended method

\begin{tabular}{llllll}
\hline Enrichment method & Detection method & Enrichment factor & Linear range $\left(\mu \mathrm{g} \mathrm{L}^{-1}\right)$ & Detection limit $\left(\mu \mathrm{L} \mathrm{L}^{-1}\right)$ & Reference \\
\hline LLE $^{\mathrm{a}}$ & FAAS & 30 & - & 13 & (Campagong and Honjo 2002) \\
CPE $^{\mathrm{b}}$ & FAAS & - & $10-200$ & 2.2 & (Shemirani et al. 2007) \\
DLLME $^{\mathrm{C}}$ & UV-Vis & - & $70-2100$ & 30 & (Kocúrova et al. 2011) \\
SPE $^{\mathrm{d}}$ & FAAS & 25 & - & 1.05 & (Tuzen and Soylak 2009) \\
USAEME & FAAS & 9.8 & $55.0-1500$ & 6.8 & This work \\
\hline
\end{tabular}

\section{aLiquid-liquid extraction}

${ }^{\mathrm{b}}$ Cloud point extraction

'Dispersive liquid-liquid microextraction

${ }^{\mathrm{d}}$ Solid-phase extraction

samples are given in Table 2. The average spiked recoveries of the analytes in water and radiological film samples were in the range of $93-105 \%$. The results indicated that the developed preconcentration method for the silver ion was not affected by potential interferences from the matrix components of the analyzed samples.

\section{Comparison with other methods}

The characteristics of the developed method have been compared with the other preconcentration methods, and the results are shown in Table 3. Table 3 indicates that characteristics are comparable in some cases or even better in other cases.

On the other hand, the USAEME method has many advantages over the other methods in Table 3, such as it uses little toxic organic material and it is faster than LLE methods. Compared to CPE, this method is faster and does not need heating and cooling of sample solution, which is a tedious process in the CPE. Compared to DLLME, the USAEME method does not need to use a third solvent (disperser solvent) for emulsification, which usually decreases the partition coefficient of the analytes into the extractant solvent (Sarafraz-Yazdi and Amiri 2010). Compared to SPE, the organic phase used for extraction is small $(200 \mu \mathrm{L})$, cheap, and more available than SPE sorbents that are more expensive than solvents used in the liquid extraction.

\section{Conclusions}

The use of ultrasound as a powerful energy for the microextraction and determination of silver was proposed. The main advantages of the method are as follows: minimum use of toxic organic solvent and wide linear dynamic range. In addition to these advantages, USAEME is simple, easy to use, inexpensive, and environmentally friendly.

\section{Additional files}

Additional file 1: Supplementary information. Table S1. effect type of extraction solvent. Figure S1. effect of $\mathrm{pH}$ on the extraction of silver ions. Figure S2. effect of centrifugation time on the extraction of silver ions. Figure S3. effect of centrifugation speed on the extraction of silver ions. (DOCX $20.5 \mathrm{~KB})$

\section{Abbreviations}

CPE: cloud point extraction; LLE: liquid-liquid extraction; LOD: limit of detection; LOQ: limit of quantification.; SPE: solid-phase extraction; USAEME: ultrasound-assisted emulsification microextraction.

\section{Competing interests}

The authors declare that they have no competing interests.

Received: 17 March 2015 Accepted: 12 January 2016

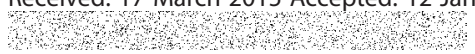

\section{References}

Aydin ME, Tor A, Ozcan S. Determination of selected polychlorinated biphenyls in soil by miniaturized ultrasonic solvent extraction and gas chromatographymass selective detection. Anal Chim Acta. 2006;577:232-7.

Bidari A, Zeini Jahromi E, Assadi Y, Milani Hosseini MR. Monitoring of selenium in water samples using dispersive liquid-liquid microextraction followed by iridium-modified tube graphite furnace atomic absorption spectrometry. Microchem J. 2007:87:6-12.

Campagong CT, Honjo T. Use of dicyclohexano-18-crown-6 to separate traces of silver(l) from potassium thiocyanate in hydrochloric acid media, and determination of the silver by atomic absorption spectrometry. Anal Bioanal Chem. 2002;373:856-62.

Dalali N, Javad N, Agrawal YK. On-line incorporation of cloud point extraction in flame atomic absorption spectrometric determination of silver. Turk J Chem. 2008:32:561-70.

De La Calle I, Pena-Pereira F, Cabaleiro N, Lavilla I, Bendicho C. Ion pair-based dispersive liquid-liquid microextraction for gold determination at ppb level in solid samples after ultrasound-assisted extraction and in waters by electrothermal-atomic absorption spectrometry. Talanta. 2011;84:109-15.

Fathirada F, Afzali D, Mostafavia A, Ghanbariana M. Ultrasound-assisted emulsification solidified floating organic drops microextraction of ultra trace amount of Te (IV) prior to graphite furnace atomic absorption spectrometry determination. Talanta. 2012;88:759-64.

Gansel EE. Determination of silver in photographic papers and films by wet ashing. Anal Chem. 1959;31:1366-8.

Hashemi M, Daryanavard SM, Abdolhosseini S. Application of ultrasound-assisted emulsification microextraction for spectrophotometric determination of trace amounts of antimony $(\mathrm{V})$ in drinking water samples using rhodamine $B$. Anal Methods. 2013;5:6848-54.

Khan S, Gul Kazi T, Soylak M. Rapid ionic liquid-based ultrasound assisted dual magnetic microextraction to preconcentrate and separate cadmium-4-(2thiazolylazo)-resorcinol complex from environmental and biological samples. Spectrochimica Acta Part A. 2014;123:194-9.

Khayatian G, Hassanpoor S. Simultaneous separation and extraction of $\mathrm{Ag}(\mathrm{I}), \mathrm{Pb}(\mathrm{II})$ and $\mathrm{Pd}(\mathrm{II})$ ions by solid phase method and determination of these ions by flame atomic absorption spectrometry. J Incl Phenom. 2012a;73:151-9.

Khayatian G, Hassanpoor S. Development of ultrasound-assisted emulsification solidified floating organic drop microextraction for determination of trace amounts of iron and copper in water, food and rock samples. J Iran Chem Soc. 2013;10:113-21.

Khayatian G, Hassanpoor S. Ultrasound assisted emulsification microextraction based on dimethyl (E)-2-[(Z)-1-acetyl)-2-hydroxy-1-propenyl]-2-butenedioate for determination of total amount of iron in water and tea samples. J Chin Chem Soc. 2012b;59:659-66. 
Kocúrova L, Balogh IS, Nagy L, Billes F, Simon A, Andruch V. Application of a bisindocarbocyanine reagent for dispersive liquid-liquid microextraction of silver with subsequent spectrophotometric determination. Microchem J. 2011:99:514-22

Koh T, Sugimoto T. Extractive spectrophotometric determination of silver (I) at the $10^{-7} \mathrm{M}$ level using 1,10-phenanthroline and tetrabromophe-nolphthalein ethyl ester. Anal Chim Acta. 1996;167:173.

Kolthoff IM, Elving PJ. Treatise on analytical chemistry, part II, vol. 4. New York: Interscience; 1966.

Li S, Cai S, Hu W, Chen H, Liu H. lonic liquid-based ultrasound-assisted dispersive liquid-liquid microextraction combined with electrothermal atomic absorption spectrometry for a sensitive determination of cadmium in water samples. Spectrochim Acta Part B. 2009;64:666-71.

Luque de Castro MD, Priego-Capote F. Analytical applications of ultrasound. Amsterdam: Elsevier; 2006

Ma JJ, Du X, Zhang JW, Li JC, Wang LZ. Ultrasound-assisted emulsificationmicroextraction combined with flame atomic absorption spectrometry for determination of trace cadmium in water samples. Talanta. 2009;80:980-4.

Manzoori JL, Abdolmohammad-Zadeh H, Amjadi M. Ultra-trace determination of silver in water samples by electrothermal atomic absorption spectrometry after preconcentration with a ligand-less cloud point extraction methodology. J Hazard Mater. 2007;144:458-63.

Mao X, Chen H, Liu J. Determination of trace amount of silver by atomic absorption spectrometry coupled flow injection on-line coprecipitation preconcentration using DDTC-copper as coprecipitate carrier. Microchem J. 1998;59:383-91.

Meian E. Metals and their compounds in environment. New York: VCH; 1991.

Mohamadi M, Mostafavi A. A novel solidified floating organic drop microextraction based on ultrasound-dispersion for separation and preconcentration of palladium in aqueous samples. Talanta. 2010;81:309-13.

Ozcan S, Tor A, Aydin ME. Determination of selected polychlorinated biphenyls in water samples by ultrasound-assisted emulsification-microextraction and gas chromatography-mass-selective detection. Anal Chim Acta. 2009;647:182-8.

Rofouei MK, Payehghadr M, Shamsipur M, Ahmadalinezhad A. Solid phase extraction of trace silver(I) using octadecyl silica membrane disks modified by 1,3-bis(2-cyanobenzene) triazene (CBT) ligand prior to determination by flame atomic absorption. J Hazard Mater. 2009;168:1184-7.

Rounaghi GH, Kazemi MS, Sadeghian H. Transport of silver ion through bulk liquid membrane using macrocyclic and acyclic ligands as carriers in organic solvents. J Incl Phenom Macrocycl Chem. 2008;60:79-83.

Safavi A, Iranpoor N, Saghir N. Directly silica bonded analytical reagents: synthesis of 2-mercaptobenzothiazole silica gel and its application as a new sorbent for preconcentration and determination of silver ion using solid-phase extraction method. Sep Purif Technol. 2004;40:303-8.

Sarafraz-Yazdi A, Amiri A. Liquid-phase microextraction. Trends Anal Chem. 2010;29:1-14.

Shamsipur M, Javanbakht M, Ghasemi Z, Ganjali MR, Lippolis V, Garau A. Separation, preconcentration and determination of trace amounts of silver ion in aqueous samples using octadecyl silica membrane disks modified with some recently synthesized mixed aza-thioether crowns containing 1,10phenanthroline sub-unit and atomic absorption spectrometry. Sep Purif Technol. 2002;28:141-7.

Shamsipur M, Khayatian G. A liquid membrane system containing dibenzyldiaza18- crown-6 for selective and efficient transport silver ions. Indian J Chem Sec A. 2001:40:594-7.

Shamsipur M, Kazemi SY, Azimi GH, Madaeni SS, Lippolis V, Garau A, et al. Selective transport of silver ion through a supported liquid membrane using some mixed aza-thioether crowns containing a 1,10-phenanthroline sub-unit as specific ion carriers. J Mem Sci. 2003;215:87-93.

Shemirani F, Rahnama Kozani R, Assadi Y. Development of a cloud point extraction and preconcentration method for silver prior to flame atomic absorption spectrometry. Microchimica Acta. 2007;157:81-5.

Stanisz E, Werner J, Matusiewicz H. Mercury species determination by task specific ionic liquid-based ultrasound-assisted dispersive liquid-liquid microextraction combined with cold vapour generation atomic absorption spectrometry. Microchem J. 2013;110:28-35.

Sil A, ljeri VS, Srivastava AK. Coated wire silver ion-selective electrode based on silver complex of cyclam. Anal Sci. 2001;17:477-9.

Tuzen M, Soylak M. Column solid-phase extraction of nickel and silver in environmental samples prior to their flame atomic absorption spectrometric determinations. J Hazard Mater. 2009;164:1428-32.
Wen X, Kong L, Chen M, Deng Q, Zhao X, Guo J. A new coupling of spectrophotometric determination with ultrasound-assisted emulsification dispersive liquid-liquid microextraction of trace silver. Spectrochim Acta Part A. 2012;97:782-7.

Zeini Jahromi E, Bidari A, Assadi Y, Milani Hosseini MR, Jamali MR. Dispersive liquid-liquid microextraction combined with graphite furnace atomic absorption spectrometry. Anal Chim Acta. 2007;585:305-11.

Zhang J-W, Wang Y-K, Du X, Lei X, Ma J-J, Li J-C. Ultrasound-assisted emulsification solidified floating organic drop microextraction for the determination of trace cadmium in water samples by flame atomic absorption spectrometry. J Braz Chem Soc. 2011;22:446-53.

Xie ZH, Xie FZ, Guo LQ, Lin XC, Chen GN. Thioacetamide chemically immobilized on silica gel as a solid phase extractant for the extraction and preconcentration of copper(II), lead(II), and cadmium(II). J Sep Sci. 2005;28: 462-70.

\section{Submit your manuscript to a SpringerOpen ${ }^{\circ}$ journal and benefit from:}

- Convenient online submission

- Rigorous peer review

- Immediate publication on acceptance

- Open access: articles freely available online

- High visibility within the field

- Retaining the copyright to your article

Submit your next manuscript at $>$ springeropen.com 